Published as: Oliver, J.J. (2017). Is "transgenerational response" a hidden cause of failed corporate turnarounds and chronic underperformance? Strategy \& Leadership, Vol. 45 Issue: 3, pp.23-29, DOI 10.1108/SL-01-2017-0006

\title{
Is "transgenerational response" a hidden cause of failed corporate turnarounds and chronic underperformance?
}

When organizations that have survived traumatic reversals - for example, product failures, ethical scandals or market disruption - attempt turnarounds, they usually seek a fresh start, adopting a new strategy and installing new leadership. But if this new initiative doesn't work and the firms continue to suffer from chronic under performance, the cause could be "transgenerational response," a potentially crippling long-term condition stemming from the trauma that occurred in the past (see the cases of AIG and Yahoo).

Transgenerational response syndrome is well known in medical and biological research. The term describes a severe environmental condition that creates a negative adaptive response in an organism. The response is transmitted to future generations and adversely influences their development and health. Healthcare research has identified, for example, adverse transgenerational effects of inadequate maternal nutrition, which harms the development and health of future generations. Even traumatic experiences can cause both physical and psychological consequences for several generations of descendants of survivors. One of the most illuminating studies into transgenerational response was an examination of the effects of post-traumatic stress disorder (PTSD) in babies of mothers exposed during pregnancy to the World Trade Center attack in 2001.[1] The study concluded that the effects of maternal PTSD, as a result of this catastrophic event, were passed on to their babies. The evidence: their significantly smaller than average birth weight and a permanent vulnerability to depression, stress related illnesses and an increased distress response to disturbing events.

\section{Do the effects of a firm's previous trauma linger?}

Firms that seemingly have recovered from past upheavals but continue to underperform may be suffering from the long-term effects of events that occurred years ago. Practitioners who have lived through one or more corporate crises have noted that the struggling firms tend to become risk averse in strategy, policies, processes and procedures. Reductions in R\&D spending and wholesale workforce cuts are likely to be counterproductive and usually lead to an exodus of talent and lowered expectation by managers who remain.

It's standard practice in such a "turnaround" situation for newly appointed executives to take swift action to rescue the staggering firm from potential failure. Their initial goal usually is to restore profitability, primarily by restructuring operations and managing costs. When survival of the firm is in sight, they can start refocusing the business on areas of future growth potential. However, when successive CEOs fail to overcome the obstacles to sustainability, then one possible diagnosis is that the firm is suffering from transgenerational response.

\section{What does this mean for business leaders?}

By looking at chronic corporate underperformance as a potential case of transgenerational response, business leaders will be able to trace the problem back to its original cause, the event that triggered the subsequent underperformance of the firm. With this perspective, they will be able to examine and respond to the 
Published as: Oliver, J.J. (2017). Is "transgenerational response" a hidden cause of failed corporate turnarounds and chronic underperformance? Strategy \& Leadership, Vol. 45 Issue: 3, pp.23-29,

DOI 10.1108/SL-01-2017-0006

inherited harmful attitudes, behaviors and adaptive cultural routines that contribute to the firms' chronic dysfunctionality.

\section{The past is the future's problem}

Not only could the lingering effects of previous trauma sabotage attempts to engage the company with new market challenges, CEOs and their management teams need to be mindful of how such unaddressed "old wounds" can hinder the management of current and future corporate crises.

The prevailing view of managing corporate crisis situations is that an effective resolution is best accomplished by adopting a systematic approach that includes preplanning, rehearsing scenario situations and reacting quickly to priority issues. However, this systematic, sequential approach may be hampered by behaviors and cultural responses related to transgenerational response. In such situations, executive teams not only need to think about managing the immediate crisis, they need to consider how their actions in the short term will affect the company in the future. For example, firms managing recent corporate crisis events - for example, VW's emissions scandal, FIFA's corruption problems, Wells Fargo's recent credit cards sales scam, or Samsung's Galaxy 7 battery fires-need to be aware of the long-term implications of their crisis-control actions. All of these events have the potential to create effects and consequences that result in adaptive and inherited responses in subsequent generations of the organization. Or, in the well-chosen words of Harvard ethicist Joseph Badaracco, "Bear in mind that a manager facing a hard problem isn't simply trying to find the right answer. He or she is also writing a sentence or paragraph in the long narrative of an organization's history and defining or redefining what it stands for."

\section{Transgenerational response: applying the theory to business practice}

The hypothesis, that transgenerational response is a significant factor in corporations that have undergone existential crises in the past, is based on exploratory research into a number of such corporate situations occurring since 2000 . The criteria for investigating transgenerational response in corporations has been informed by research methodology from health and life sciences literature; the three defining variables are:

1. Identifying a critical corporate incident.

2. Defining a corporate generation.

3. Measuring chronic corporate underperformance.

\section{Identifying a critical corporate incident}

These incidents are clearly identifiable and result in subsequent corporate effects and consequences that affect the viability and development of the firm. The initial review of corporate crisis situations ranged from scandals to disasters and included such incidents as: (1) Parmalat's accounting fraud (2003) which resulted in the \$20 billion bankruptcy of the firm. (2) Hewlett-Packard's spying scandal (2006) which resulted in criminal charges being filed against senior executives of the firm. (3) BP's Deep Water Horizon disaster (2010) which resulted in a significant clean-up bill for the firm and a Justice Department environmental fine of $\$ 21$ billion. 
Published as: Oliver, J.J. (2017). Is "transgenerational response" a hidden cause of failed corporate turnarounds and chronic underperformance? Strategy \& Leadership, Vol. 45 Issue: 3, pp.23-29, DOI 10.1108/SL-01-2017-0006

\section{Defining a corporate generation}

From the perspective of the management team, a corporate generation starts with the appointment of a new CEO and ends when that executive is replaced. It is a period in the life of a firm that is distinctive with each new CEO making major corporate decisions, shaping long-term strategy and ultimately being responsible for delivering on corporate objectives and performance targets. In the US the average tenure of an S\&P 500 CEO in 2014 was 9.9 years.[2] So a CEO's tenure that is less than this average figure could be indicative of an underperforming firm. But a firm suffering a traumatic incident that then appoints and replaces several CEOs in a relatively short space of time could be experiencing transgenerational response effects.

\section{Measuring chronic corporate under performance}

Chronic corporate underperformance was measured by persistent declines in market capitalisation, operating income, EBIT, and share price performance as compared with stock market indices and competitors. These financial metrics were chosen for their ease of use and longitudinal comparison.

The average percent increase or decrease in each financial variable in the years before and after the "Critical Corporate Incident" was then calculated to illustrate corporate financial performance. For example, if a critical corporate incident occurred in 2006, the market capitalization of the firm in 2006 was compared with the average market capitalization figure prior to and following the event. The percent change in pre- and post-event averages were then compared to assess corporate performance effects of the event.

The application of these criteria to a range of critical corporate incidents resulted in a number of cases where all three indicators of possible transgenerational response could be documented. However, in some cases a critical corporate incident was followed by chronic corporate underperformance, but a rapid turnover of CEOs did not take place These cases included: Time Warner (AOL merger, 2002); Sears Holdings (KMART merger, 2004); Toyota Motor Corp (Sudden Unintentional Acceleration product recall, 2009); Daimler AG (bribery to secure government contracts, 2010); Olympus Corporation (accounting scandal, 2011); Walmart (US/Mexico bribery scandal, 2012); Carnival Corp (Costa Concordia disaster, 2012).

\section{Transgenerational response: the evidence from two cases}

The following two cases present evidence that transgenerational response is a concept that can be applied to the business arena and can explain chronic corporate under performance.

\section{Case: American International Group (AIG)}

On February 2 2005, AIG executives were charged with accounting fraud and bid rigging by the US Securities and Exchange Commission, the U.S. Justice Department and the New York State Attorney General's Office. The $\$ 3.9$ billion fraud booked loans as revenue, a practice that was designed to inflate AIGs share price. In addition to sullying the company's reputation, the consequences of this deception 
Published as: Oliver, J.J. (2017). Is "transgenerational response" a hidden cause of failed corporate turnarounds and chronic underperformance? Strategy \& Leadership, Vol. 45 Issue: 3, pp.23-29,

DOI 10.1108/SL-01-2017-0006

were a $\$ 1.64 \mathrm{bn}$ fine by the US Securities and Exchange Commission and the firing of long-serving AIG CEO Maurice Greenberg.

Since this event, AIG has appointed six CEOs who have been unable to manage the effects of this event (Exhibit 1). While one can argue that the effects of the global financial crisis of 2008, and the resulting massive corporate losses that necessitated a US federal government bailout, have clearly influenced the performance of AIG, the data indicates that things started to go wrong from the date that the executives were charged with accounting fraud. Exhibit 2 shows that the average values of Market Capitalisation, Operating Income and EBIT before the Critical Corporate Incident are in stark contrast to the pre- and post-event figures. The stock indices comparison in Exhibit 3 also indicates that compared with the S\&P 500 and The Chubb Corp, a major competitor, the AIG stock price started to drift from February 2005 and has subsequently failed to recover. On March 9, 2017 The New York Times reported that "A little over a year after staving off calls by activist investors to break up the American International Group, Peter D. Hancock, the insurance giant's chief executive, said on Thursday that he would resign after investors had lost faith in his efforts to turn around the company. Last month, the insurer reported a fourthquarter loss of $\$ 3.04$ billion - one of its worst quarters since the 2008 financial crisis and a major setback in Mr. Hancock's efforts to reshape the company."[3]

\section{Exhibit 1: AIG Corporate Generations}

\begin{tabular}{|c|c|}
\hline CEO Tenure & AIG Corporate Generations (CEOs) since 2005 \\
\hline $2017-$ current & Duperreault \\
\hline $2014-2017$ & Hancock \\
\hline $2009-2014$ & Benmosche \\
\hline $2008-2009$ & Liddy \\
\hline $2008-2009$ & Willumstad \\
\hline $2005-2008$ & Sullivan \\
\hline $1968-2005$ & Greenberg \\
\hline
\end{tabular}

\section{Exhibit 2: AIG Financial Performance}

\begin{tabular}{|l|c|r|r|c|}
\hline & $\begin{array}{c}\text { Pre- } \\
\text { Incident } \\
\mathbf{5 y r} \\
\text { Average } \\
(\mathbf{2 0 0 0 - 0 4 )}\end{array}$ & $\begin{array}{c}\text { Critical } \\
\text { Corporate } \\
\text { Incident (2005) }\end{array}$ & $\begin{array}{c}\text { Post- } \\
\text { Incident } \\
\mathbf{1 0 y r} \\
\text { Average } \\
\mathbf{( 2 0 0 6 - 1 5})\end{array}$ & $\begin{array}{c}\text { Change } \\
\text { in Pre \& } \\
\text { Post } \\
\text { Incident } \\
\text { Averages } \\
(\boldsymbol{\%})\end{array}$ \\
\hline Market Value (US\$ Mn) & 176032 & 142953 & 77573 & -56 \\
\hline Operating Income (US\$ 000) & 14585400 & 21336000 & 9364300 & -36 \\
\hline EBIT (US\$ 000) & 15171000 & 20947000 & 2562000 & -83 \\
\hline
\end{tabular}

Source: Adapted from Thomson Reuters Datastream 


\section{Exhibit 3: AIG long-term Share Price Performance (2005-2016)}

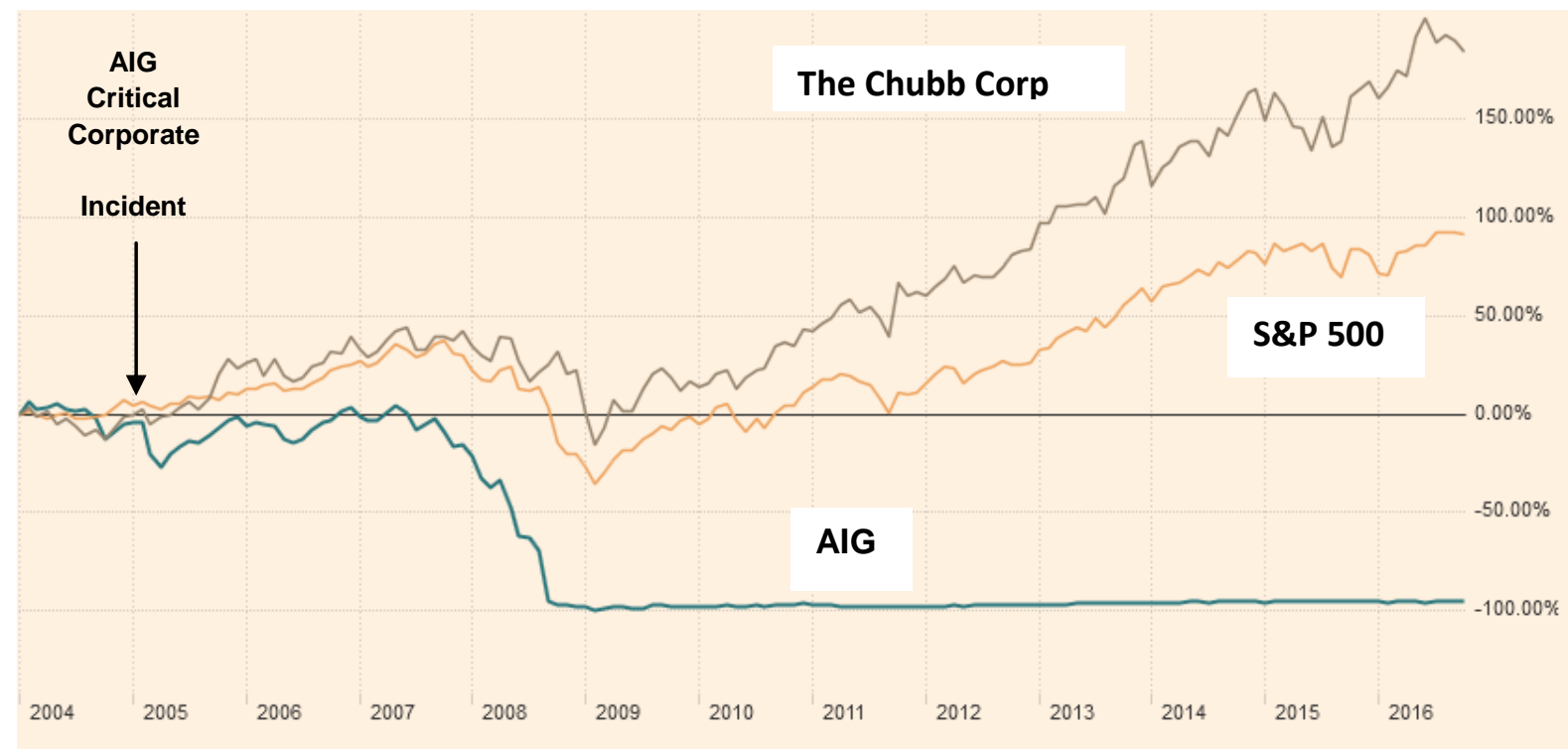

Source: FT.com

\section{Case: Yahoo Inc.}

On February 1, 2008, Microsoft Corporation made a hostile bid to acquire Yahoo for US $\$ 44.6$ billion in an attempt to combat the growing power and dominance of Google. The proposed acquisition made sense on a number of levels for both parties, but ultimatel collapsed due to the differences of opinion in the valuation of Yahoo. Things haven't been the same for Yahoo since this Critical Corporate Incident. The fallout from this hostile bid has affected subsequent generations of Yahoo managers who have had six CEOs take the helm (Exhibit 4).

While Yahoo have been hiring and firing CEOs, changing strategy, restructuring operations and cost-cutting, Google has been innovating, dominating market share and expanding the strategic scope of its activities with impressive results. Yahoo's financial performance has been variable since the 2008 event, with declines in the average market value and operating income figures, before and after the Critical Corporate Incident. The long-term share price performance of Yahoo compared with Google (Alphabet Inc.) and the NASDAQ also reflects a mostly sluggish performance by Yahoo.

One performance measure that doesn't fit neatly into the underperformance picture is Yahoo's EBIT number, which has grown significantly since 2008 and demonstrates the firm's ability to generate earnings from operations (Exhibit 5 and Exhibit 6). 
Published as: Oliver, J.J. (2017). Is "transgenerational response" a hidden cause of failed corporate turnarounds and chronic underperformance? Strategy \& Leadership, Vol. 45 Issue: 3, pp.23-29,

DOI 10.1108/SL-01-2017-0006

Exhibit 4 Yahoo corporate generations

\begin{tabular}{|c|c|}
\hline CEO Tenure & Yahoo Corporate Generations (CEOs) since 2008 \\
\hline 2012 -current & Mayer \\
\hline $2012-12$ & Levinsohn \\
\hline $2012-12$ & Thompson \\
\hline $2011-12$ (interim) & Morse \\
\hline $2009-11$ & Bart \\
\hline $2007-09$ & Yang \\
\hline
\end{tabular}

Exhibit 5 Yahoo financial performance

\begin{tabular}{|c|c|c|c|c|}
\hline & $\begin{array}{c}\text { Pre- } \\
\text { Incident } \\
\mathbf{7 y r} \\
\text { Average } \\
\mathbf{( 2 0 0 0 - 0 7 )}\end{array}$ & $\begin{array}{c}\text { Critical } \\
\text { Corporate } \\
\text { Incident } \\
\mathbf{( 2 0 0 8 )}\end{array}$ & $\begin{array}{c}\text { Post- } \\
\text { Incident } \\
\mathbf{7 y r} \text { Average } \\
\mathbf{( 2 0 0 9 - 1 5 )}\end{array}$ & $\begin{array}{c}\text { Change } \\
\text { in Pre \& } \\
\text { Post } \\
\text { Incident } \\
\text { Averages } \\
(\boldsymbol{\%})\end{array}$ \\
\hline Market Value (US\$ Mn) & 30810 & 35978 & 26686 & $-13 \%$ \\
\hline Operating Income (US\$ 000) & 531499 & 607354 & 521521 & $-2 \%$ \\
\hline EBIT (US\$ 000) & 571733 & 95801 & 1278365 & $+124 \%$ \\
\hline
\end{tabular}

Exhibit 6 Yahoo long-term Share Price Performance (2008-2016)

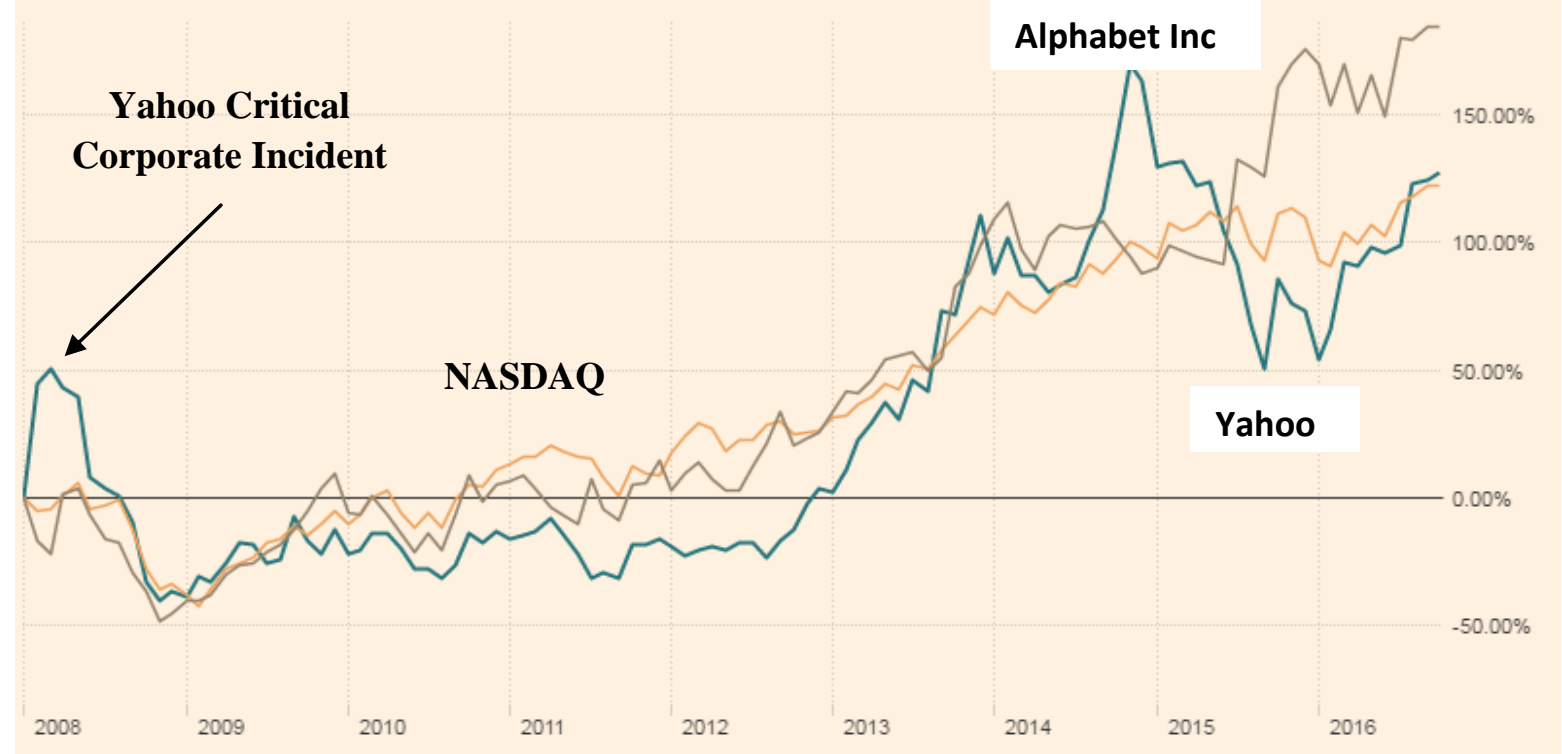

Source: Adapted from Thomson Reuters Datastream 
Published as: Oliver, J.J. (2017). Is "transgenerational response" a hidden cause of failed corporate turnarounds and chronic underperformance? Strategy \& Leadership, Vol. 45 Issue: 3, pp.23-29,

DOI 10.1108/SL-01-2017-0006

\section{Taking action}

Perhaps it's time to consider a provocative alternative diagnosis when companies with a history of existential crisis subsequently experience a number of years of chronic corporate underperformance and unproductive turnaround attempts. When such situations can't be resolved by a change in strategy or a new CEO, it's possible the organization is suffering a stress reaction that is hampering its ability to successfully address new challenges. By looking at chronic corporate underperformance through the perspective of transgenerational response, business leaders can address the lasting effects of a historic critical corporate incident. So what more do business leaders need to know and what action should they take if they suspect the presence of transgenerational response in their firm?

The first step is to acknowledge the existence of dysfunctional adaptive responses, inherited attitudes and behaviors that have become embedded in the corporate culture to the detriment of the long-term viability and performance of the firm. For example, a firm that has been exposed to a traumatic event would likely be more risk averse, and so evidence of this would be found in strategy documents; policies, processes and procedures; reductions in R\&D spending or wholesale and counterproductive workforce cuts.

The research presented so far is preliminary. The evidence in the case studies of AIG and Yahoo supports the hypothesis that a critical corporate incident produced the consequential effect of chronic poor financial performance in both firms. Obviously a larger sample size is needed to provide conclusive proof. It would also be helpful to study firms that recovered rapidly after trauma to learn how they managed their revival.

Without such studies it's difficult to generalize about how to overcome post-traumatic stress. The literature is full of turnover advice-change the strategy, change the culture, hire a CEO from outside the industry - but if the hidden cause is transgenerational response, it would be hard to justify prescribing one of these solutions. We can hope that the provocative diagnosis - transgenerational response - will enable strategists to review the advice available in the literature with a new understanding and then experiment with better ways to mitigate damage from the trauma and move on to recovery.

\section{Notes}

1. Yehuda, R., Engel, S.M., Brand, S.R., Seckl, J., Marcus, S.M. and Berkowitz, G.S. (2005). "Transgenerational effects of posttraumatic stress disorder in babies of mothers exposed to the World Trade Center attacks during pregnancy," The Journal of Clinical Endocrinology \& Metabolism, 90(7), pp. 4115-4118.

2. Tonello, M. (2015). "New Statistics and Cases of CEO Succession in the S\&P 500," The Harvard Law School Forum on Corporate Governance and Financial Regulation (https://corpgov.law. harvard.edu) 
Published as: Oliver, J.J. (2017). Is "transgenerational response" a hidden cause of failed corporate turnarounds and chronic underperformance? Strategy \& Leadership, Vol. 45 Issue: 3, pp.23-29, DOI 10.1108/SL-01-2017-0006

3. "A.I.G.'s Chief Executive to Resign After Turnaround Setback," The New York Times, March 9, 2017.

www.nytimes.com/2017/03/09/business/dealbook/aigs-chief-executive-to-resignafter-turnaroundsetback.html?\&hp\&actionclick\&pgtypeHomepage\&clickSourcestoryheading\&module second-column-region\&regiontop-news\&WT.navtop-news\&_r0 